\title{
Information Systems as an Enabler for Creating Networks for Modernization, Transparency and Accountability of the Social Economy Sector
}

\author{
Rui Pedro Marques ${ }^{1,2 \star}$, Carlos Santos ${ }^{1,3}$, Rúben Duarte ${ }^{1}$
}

${ }^{1}$ ISCA, University of Aveiro, Aveiro, PORTUGAL

${ }^{2}$ Algoritmi, University of Minho, Guimarães, PORTUGAL

${ }^{3}$ CICF, IPCA, Barcelos, PORTUGAL

*Corresponding Author: ruimarques@ua.pt

Citation: Marques, R. P., Santos, C. and Duarte, R. (2020). Information Systems as an Enabler for Creating Networks for Modernization, Transparency and Accountability of the Social Economy Sector. Journal of Information Systems Engineering and Management, 5(4), em0128. https://doi.org/10.29333/jisem/8533

\section{ARTICLE INFO}

Published: 8 Sep. 2020

\begin{abstract}
The current digital transformation may impact on the economic and social aspects of entities of the social economy and on the practices of accountability. The accountability is, in some cases, a mandatory requirement for those entities and an element of recognized merit for the good management. This paper aims to present a component developed in a more comprehensive project, in the context of Private Institutions for Social Solidarity (IPSS) in Portugal. This component, using technologies and information systems and a SaaS Multi-tenant approach, consists of a database and a web platform which collect, process, store and disseminate data and indicators (substantiated and supported by a conceptual framework) capable to assess the financial, social and economic impact of the IPSS in Portugal. Therefore, this work helps these entities to be more accountable and to comply with legal requirements. The innovation and relevance of this project is related to its capability of enabling transparency and accountability and promoting entities' performance. Based on the Design Science methodology, this paper conceptually presents the digital platform that supports the project.
\end{abstract}

Keywords: multi-tenancy, SaaS, cloud, accountability, social economy, design science

\section{INTRODUCTION}

In order to have a society which is supportive and fair to the excluded and/or the minorities, many entities, included in the social economy sector, are constituted by private and non-profit initiative. However, despite the extreme importance of this sector in the society, these entities face pressures for greater accountability towards their stakeholders because most of services and activities provided by these entities are supported by public funds, so there is more attention on how that funds are managed. In addition, there is too much media coverage to bad examples in this sector. Even though these cases represent a very small part of the sector's reality, they lead to the discrediting of these entities by the stakeholders.

Thus, these entities need to improve the dissemination of their good practices and the social impact they have on the community. Therefore, there is a need for financial, social and economic indicators to assess the performance and the impact of these entities in particular, and of the sector in general.

In addition, there are some legislative and regulatory pieces which establish a financial supervision model, applicable to these entities, based on demanding mandatory rules, with a view to increasing the accountability of their management. For example, in Portugal, the Decree-Law 172-A/2014 establishes, in article 14-A that financial reports for the previous year must be published on the entity's website by May 31 of the following year. However, the overwhelming majority of entities do not make this disclosure, nor are they even able to do so because they do not have an institutional website (Ferreira et al., 2016, 2019).

After the publication of this Decree-Law, only a minority of entities had an institutional website in February 2016, that is, only $37.62 \%$ of them had a website and, of these, only $6 \%$ disclosed financial information (Ferreira et al., 2016). A year later, the percentage of entities with a website remained, however, of these, only $23 \%$ started to disclose financial information. Although the percentage of entities that disclose financial information has increased, we are still facing a very high number of entities which do not comply with the legal requirements (Ferreira et al., 2019)

Thus, the project TheoFrameAccountability (Theoretical framework for promotion of accountability in the social economy sector: the IPSS case) aims to promote the accountability, of the social, financial and economic dimensions, in the social economy 
sector in Portugal. It is being executed by University of Aveiro, Polytechnic Institute of Porto, Polytechnic of Coimbra and National Confederation of Solidarity Institutions and it mainly intends to provide tools for the online dissemination of mandatory and voluntary information about these entities, that covers the social, financial, and economic aspects of their activities. It also aims to conceptualize a framework which allows the stakeholders to make the assessment of the impact of these entities and of the social economy sector.

Thus, this paper presents the conceptualization of the technological component of this project (Marques, Santos and Duarte, 2019, 2020). This component includes the development of a digital platform that provides these entities with an institutional and individual website on that platform so that they can disclose their organizational information, mandatory and voluntary, complying with the legal requirements. The development of this component is based on the SaaS (Software as a Service). As this website will be used for each participating entity, common resources are shared while maintaining logical independence [3], we are also facing a multi-tenant architecture.

The SaaS multi-tenant approach used in this project allows to create a network of entities of the social economy sector, enabled by the digital platform presented in this paper, gathering data of different natures which contribute to the transparency and accountability of the entities participating in this network. The digital platform is responsible for providing mechanisms for collecting, processing and storing data to determine and disseminate the indicators that make up the conceptual framework of indicator about the social, financial and economic performance of the participating entities. This type of networks establishes the bridge between social innovation and service innovation through a multi-agent framework or platform (Windrum et al., 2016).

This paper, in addition to this introduction, is structured as follows: in section 2 the literature review is presented; section 3 presents the methodology; then, the conceptualization of the digital platform developed is presented in section 4; and, finally, in the last section, some final considerations are presented.

\section{LITERATURE REVIEW}

\section{Transparency and Accountability}

A recent systematic literature review (Santos et al., 2019) concluded that studies on the social economy are still very few, despite the tendency of growing. It stated that modernization has an impact on the economic and social aspects of entities of the social economy and also showed that the practice of transparency and accountability are elements of recognized merit for the good performance of these entities.

Despite the lack of precision in the use of the concept, transparency can be seen as a means capable of bringing respectability to organizations (Christensen and Cornelissen, 2015), but also as the solution for organizational ethics lapses (Rawlins, 2009). It is currently considered a value considered almost indispensable in organizations. Ball (2009) concludes that the definition of transparency reveals three metaphors: transparency as a public value adopted by society against corruption; transparency as a synonym for open decision-making by governments and non-profit organizations and transparency as a complex tool for good governance in programs, policies, organizations and nations. There are authors who define transparency as a process that involves not only the availability of information, but also active participation in the acquisition, distribution and creation of knowledge (Cotterrell, 1999; Turilli and Floridi, 2009). Rawlins (2009) states that transparency consists of making available all the information legally published and presents the concept based on three important elements: true, substantial and useful information; stakeholder participation in identifying the information they need; objective reporting of activities and policies.

Another perspective characterizes transparency in a dynamic and intensive information sharing process, facilitated by Information and Communication Technologies (ICT) (Bertot, Jaeger and Grimes, 2010) and, consequently, more transparent operations based on an interaction between organizations and their stakeholders to share information and cooperate with each other (Vaccaro, 2012). Essentially, it means being authentic in the way they communicate externally to stakeholders and also within the organization. The digital transformation we are currently experiencing makes information dissemination through institutional websites more dynamic (Meijer, 2015).

Marshall et al. (2018) discusses the role of data technologies in Charitable Organizations (charities) and how socio technical systems that are used by organizations affect these practices. Marrone and Hazelton (2019) highlight the importance of the role of new ICT for the development of a culture of accountability. However, they call attention to the need to deal with the disruptive power of these technologies. Devlieghere, Bradt and Roose (2019) developed a study in which they concluded that information systems are important as facilitators of accountability practice. However, some managers show some fear that this practice will be held hostage by the referred systems. The use of business intelligence tools as facilitators of the construction of dashboards with a new communication approach may be relevant to the practice of accountability (Li and Liu, 2016).

Some frameworks to promote transparency and accountability in its various dimensions are still very scarce. There are some studies on accountability, but not all on the social economy sector (Santos et al., 2019). For example, there is a study that developed a practical framework which can be used to explore how accountability within social enterprise organizations is constructed and discharged. However, while a framework for better understanding accountability od these organizations is presented, it is not empirically tested (Connolly and Kelly, 2011).

Another study (Tenbensel, Dwyer and Lavoie, 2014), presented a conceptual framework for analyzing accountability tensions experienced by third-sector organizations which could assist managers and other stakeholders with the difficult task of designing more workable and meaningful accountability regimes for all stakeholders. 
There is also an index (Santos et al., 2018) that focus on the maturity of the institutional websites of the entities of the State's direct and indirect administration. This index can be adapted to evaluate and monitor the accountability practice of social economy entities. It holistically encompasses, in addition to online presence, three relevant dimensions associated with the practice of accountability: the quality of the website; financial and performance reporting online; and the services available on the website. This can be very useful to assist possible improvement actions on the institutional websites of social economy entities and to motivate stakeholders. The index's authors add that this index should be periodically reviewed to assess the need to introduce improvements due to the technological advances that are taking place and also to the evolution of the legislative and regulatory framework related to e-government.

\section{SaaS Multi-tenant Digital Platforms}

The use of ICT, being part of a more comprehensive modernization process, can be used for the creation of institutional websites for entities of the social economy sector. In this way, they will be able to disclose financial and non-financial information so that all their stakeholders can assess their performance and, consequently, improve their accountability (Santos et al., 2019). The evolution of digital platforms and cloud computing poses new challenges to the accountability of organizations that use these technologies to disseminate their mandatory or voluntary information. There are already some works, albeit few, on the perspective of accountability as a service (Bender et al., 2007; Yao et al., 2010).

The concept of digital platform points to a constellation of digital arrangements that serve to organize social and economic activity (Kenney and Zysman, 2016). These authors state that digital platforms are some of the technological characteristics that define the current era consisting of intelligent tools (Industry 4.0). In addition, the concept of cloud computing and mobile computing offers an unprecedented potential for computing power, allowing for the creation of infrastructures that are a fertile ground for the development and implementation of digital platforms (Gustavsson, 2017).

The concept of digital platform in business contexts includes three main functions: interaction interface, value creation and network formulation (Rong et al., 2013). Interaction interface means that members of the ecosystem should have the skills to leverage the interface as a type of tool to build their own products. Value creation means that the platform should allow ecosystem partners to work together to create value. Network formulation means that if the platform provides conditions for partners to work together to create value together, they will be able to formulate specific network standards themselves to compete with their competitors' ecosystems.

Digital platforms and cloud computing are fundamental characteristics of the current phase of the digital revolution. These technological paradigms are integrated with what we call intensive computing. At the origin of this concept is a huge capacity of computing power that allows the generation and analysis of data on a scale never imagined before, allowing for the reorganization/ transformation of different types of services (Zysman and Kenney, 2017).

Digital platforms are the basis on which an increasing number of activities based on the link of other diverse activities (e.g. market, social and political) have been organized. If the industrial revolution happened around the factory, today's changes are organized around digital platforms and processing processes that support huge data repositories using cloud computing. The relevance of these digital platforms suggests that we are in the midst of a reorganization of our economy (Lewandowski, 2013).

With the maturation of cloud computing, the SaaS (Software as a Service) model emerged, in which part of the software and its management is outside the physical control of the organization. Organizations may purchase the software services instead of buying the software. Thus, responsibility for managing the software is transferred to third parties, reducing the cost and improving the performance of organizations. Some advantages of the SaaS model are the ubiquity and scalability of the services as well as the greater security and reliability of data (Guo and Ma, 2018).

The multi-tenancy architectures, also in the contexts of cloud computing, may offer a relevant contribute, because this approach allows that a single instance of the software is run on the service provider's infrastructure, and many tenants access the same instance, as if it were a dedicated environment (Karatas et al., 2017; Tizzei et al., 2017). Multi-tenancy is designed to increase the cost-benefit ratio by sharing available resources across organizations and users (called tenants).

Multi-tenant SaaS applications are subject to customization, with respect to the specific requirements of each tenant, ensuring that the management of the SaaS application remains feasible in contexts of an increasing number of tenants and co-existing tenant customizations (Truyen et al., 2016).

\section{METHODOLOGY}

The Design Science methodology was chosen to conduct this research, specifically for the development of the technological component (Marques, Santos and Duarte, 2019, 2020). This research methodology is appropriate for this part of the project because it has as main purpose to solve a problem or a specific need through the conceptualization, development and evaluation of technological artifacts, not forgetting sustainability business models and social responsibility (Hevner, 2007; Hevner and Chatterjee, 2010; Upward and Jones, 2016).

This methodology is composed of six steps (Peffers et al., 2007):

1. problem identification and motivation;

2. definition of the solution's objectives;

3. conceptualization and development;

4. application; 
5. evaluation;

6. disclosure.

Instantiating the methodology in this research, the step 1 (problem identification and motivation) is related to the main objectives of the project, which are:

- help the entities of the social economy sector to comply with the legal requirements, namely in the preparation and online dissemination of a more appropriate report of its results, through the provision of an institutional website on the platform of this project;

- digitally support the set of indicators that make up the framework, namely in the collection, management and store of data and in the determination and dissemination of indicators;

- and promote accountability in the social economy sector, through the achievement of the previous objectives, reinforcing the credibility of entities and increasing the trust of their stakeholders.

The step 2 (definition of the solution's objectives) included an ethnographic methodology, in order to improve our understanding of human thought and action through interpretation of human action in context (Myers, 1997), in which the project's researchers were involved actively with the entities' stakeholders, in order to undertake active learning, through participation in the context of the reality experienced in these entities, existing practices and processes. This step, together with a literature review on the topic, allowed to develop a set of information needs of a financial, social and economic nature that could characterize the performance and impact of the entities.

The conceptualization and development of the platform (step 3), which intends to be a solution that allows an individual website for each participating entity and that can disclose on it the financial information required by law. This proposed solution has to collect, store and process data in order to produce indicators that allow the financial, social and economic impact of the activity of the entities to be assessed. More details about the conceptualization are presented in the next section of this paper.

The step 4 (application) - is based on a case study in a real environment, with the participation of several Portuguese entities which voluntarily joined the project TheoFrameAccountability. In this set of participants, we will have entities of different legal natures, dimensions, with varied social responses and geographically dispersed.

The step 5 (assessment) will be carried out on two phases. On one phase, shortly after development, the platform's quality assessment will be made regarding its functional suitability, performance efficiency, compatibility, usability, reliability, security, maintenance and portability, according to the ISO/IEC 25010:2011 standard. In the other, after conceptualization, a Focus Group will be used, including academics, decision makers and other stakeholders and experts from the social economy sector, who, in addition to validating the indicator framework, will also analyze the adequacy of the platform with regard to usability and its efficiency in promoting transparency and disclosing the performance and impact of entities. It is intended that the Focus Group has an impact on improving conceptualization and defining the objectives and requirements of the platform solution.

Finally, the step 6 (disclosure) will be made in workshops with the stakeholders of the sector, in order to publicize the platform as a repository of relevant indicators for both decision makers, academics and researchers; with the entities to promote the platform as a tool to increase transparency and, consequently, credibility, in order to attract more participating entities; in the scientific community, through conference communications and journal papers; and in a final event to disseminate the results of the project TheoFrameAccountability.

\section{SOLUTION PROPOSAL}

The literature review, the active participation of researchers with the entities and their stakeholders, the Focus Group referred to in the methodology section, allowed to perceive and reinforce the interest in the development of a digital platform to support the framework of indicators, but also as a tool to assist entities both in complying with legal requirements and in improving their accountability. Figure 1 shows the functional architecture of the support platform for this project. The functional architecture is responsible to represent how the functions will operate together to perform the system mission(s) (US Air Force, 2004).

From Figure 1, we can see the following core components:

- Web Server and Database;

- Portal and Entities' Institutional Website;

- Entities' Website Management and Surveys;

- Framework Front-End

The Web Server and Database are the components which interact directly and indirectly with all the others, because they store and manage all the data in the indicator framework, as well as the data that feed the individual website of each entity participating in the project (tenant).

In addition to presenting the project and its features, the Portal will:

- highlight news and/or events from participating entities;

- search entities through a set of filters; 


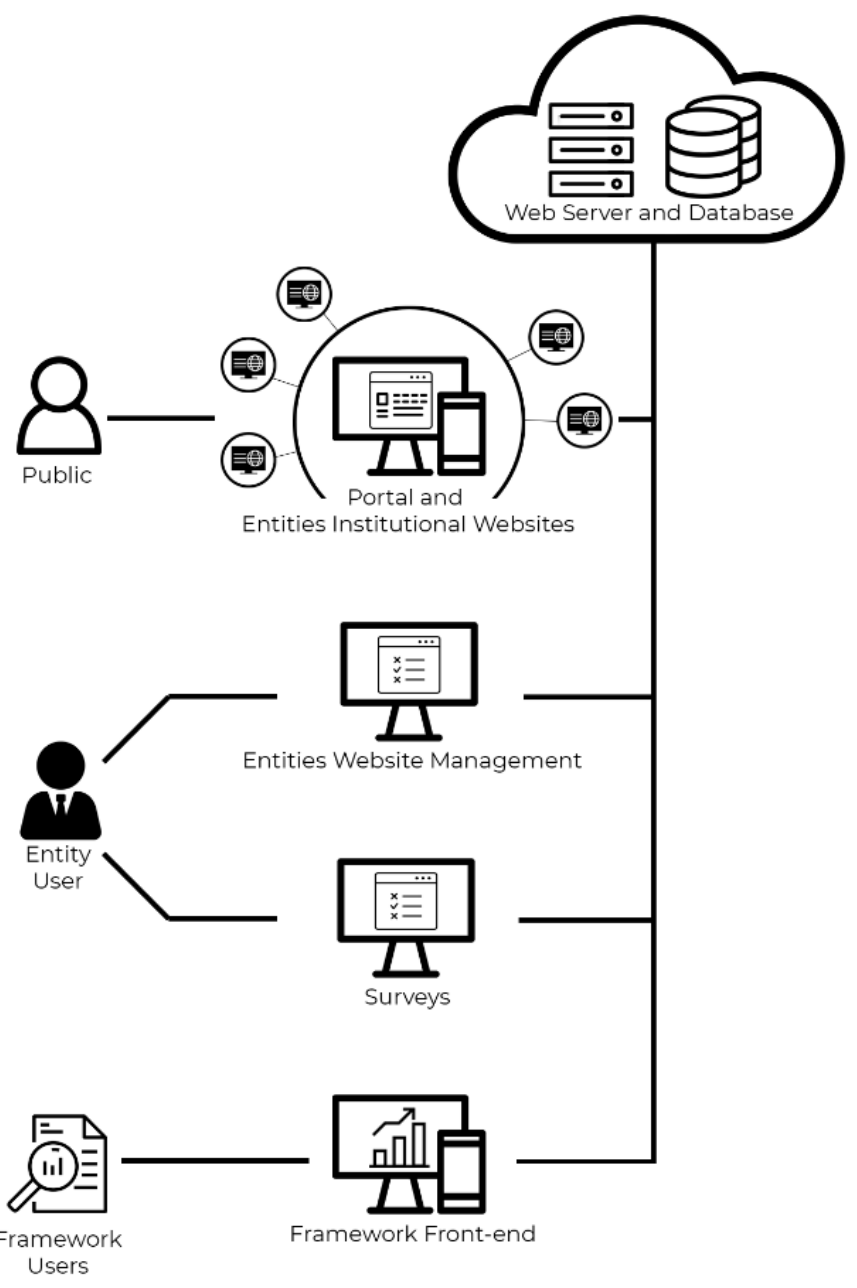

Figure 1. Functional architecture of the solution proposal (Marques, Santos and Duarte, 2020)

- consult, in aggregate form, the participants' institutional information;

- access the front-end of displaying the framework's indicators.

As for the Entities' Institutional Website, a customizable website will be made available to each participant, so that entity can use it as an institutional website, disseminating institutional information, news and even the legally required accountability reports, as well as other information voluntary

The Entities' Website Management and Surveys is a back-end for every participating entity, for managing their individual website and editing the information contained therein. In addition, there will be an area for collecting the data necessary to determine the framework's indicators. These data will be collected through forms that provide adequate survey questionnaires addressed to the entities. Furthermore, other data entry mechanisms will be made available, namely mechanisms for uploading documents already delivered to other entities, so that data entry in the database is automated, and does not require manual entry of all data.

The Framework Front-end is the platform area in which the various indicators that make up the framework are presented, allowing the analysis of these indicators by different dimensions of analysis and a longitudinal observation of the sector's performance.

Figure 2 shows a block diagram with the main features made available on the entities' institutional websites on the Portal, complementing the understanding of the articulation and flow of data in the main components of the functional architecture. In this figure, two individual websites (tenants) are represented to illustrate. But this block will be replicated as many times as the participating entities, which, in turn, will all be communicating with the Portal.

Regarding the Portal Back-end, we note that it is composed of three main features:

- Registration of the entity on the platform as a participant;

- Management of participants on the platform, which includes, for example, the validation of the institutions' records and the management of credentials and access to platform users;

- Management of inquiries by the project administrator, namely its creation and edition to allow the calculation of the framework's indicators; and verification of inquiries that are still to be answered by the entities, so that there are alerts for completion. 


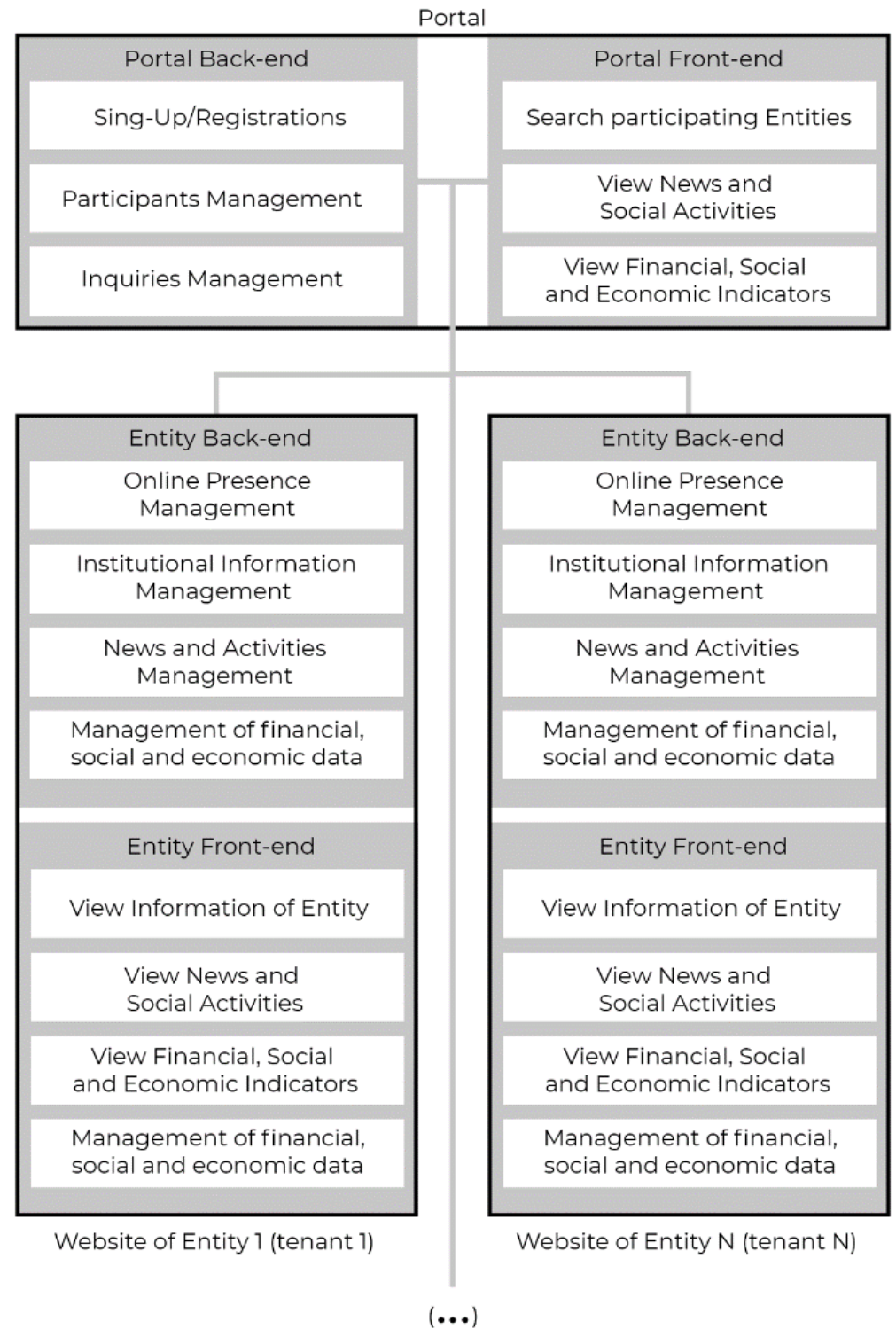

Figure 2. Block diagram of the platform (Marques, Santos and Duarte, 2020)

Regarding the Portal Front-end, for access to the public, it is possible to:

- Search participating entities, in order to be directed to the respective individual websites;

- Consult, in aggregate form, information regarding the participating entities (institutional information, news and events dissemination;

- Access the financial, social and economic indicators of the framework (functionality only available to the registered users on the platform and with an authorized use profile - Framework User).

Regarding the back-end of each entities' institutional website, for the entities' exclusive use (Entity Back-end), the user is able to:

- Management of online presence, such as the choice of aspects related to the template of its website, formats and other available web design options;

- Management of institutional information made available on its individual website;

- Creating and editing news and events to be made available online;

- Inserting and updating financial, social and economic data (required by law and voluntary).

On the front-end of each entity's individual website (Entity Front-end), which is accessible to the general public, it is possible to view all the information inserted in the back-end in the format and structure defined in the template chosen by the entity.

Based on Figure 1, on its description, and on the exposed in relation to Figure 2, it is possible to identify four different usage profiles: Public; Entity User; Framework User; and Administrator.

- The Public is an unregistered user on the platform, who can access the portal front-end and all its features as well as the individual website of the entities and all the information available there. Access to individual website can be done through 
the direct URL of the same, created when registering the entity on the platform (portal back-end), or through the search engines of entities on the portal front-end.

- The Entity User is a registered and validated user on the platform, who is responsible for managing the entity's website on the back-end of the respective individual website, as well as for inserting and managing all the data and information provided on the respective website. It is also responsible for responding to existing surveys, providing the necessary data for the determination of the framework's indicators.

- The Framework User is an user with permission to access the framework's indicators, being authorized to consult the list of indicators by analysis dimension, to consult the data for each of the indicators, and to download the data for each indicator, for further studies.

The Administrator is an user responsible for managing the platform, namely, validating the entities' records, consulting the surveys that are still waiting for a response and triggering alerts to the respective entities with delayed responses, and removing the individual websites of public access, if their content does not comply with the platform usage policies.

\section{FINAL CONSIDERATIONS}

This paper presents the conceptual and methodological part of a technological component of a more comprehensive research, still in progress. This component is a digital platform based on a SaaS multi-tenant model. The objectives, requirements and the main aspects of design and development of this digital platform are presented.

The main objective of the comprehensive research project (TheoFrameAccountability) is to design a framework of indicators that allows to assess the financial, social and economic impact of entities in the social economy sector, thus promoting their accountability. The platform presented in this paper gives the technological support to the operationalization of this project objective. Moreover, the solution presented in the paper also includes the provision of an institutional website for the participating entities so that they can use to comply with the legal requirement to disclose the accountability reports.

The multi-tenant model is justified for the platform here presented because it will be used by multiple entities. Thus, the platform will include several instantiations of individual websites, one for each entity (tenant).

The solution presented is based on the SaaS model since all users of the platform, but particularly participating entities, will be able to use the platform as if it were a service, without the need to install, update or maintain any hardware, middleware or software. Users will use the solution's features directly in the browser without having to install any software, on any computer or mobile device connected to the Internet, since the data will be stored in the cloud.

The main limitation of this paper is the fact that the work is still in progress, and it is not possible to present results, quantitative or qualitative. It is therefore a conceptual paper whose work will require future validation.

However, the importance of the work presented in this paper is not in the technological innovation of the platform, but is rather related to the innovative character of the main purpose of the project TheoFrameAccountability, as well as the impact it will have on promoting accountability in the social economy sector. And this contribution to the sector is quite evident when we analyze the data presented in the introduction of the paper and notice the high percentage of entities that do not comply with the legal requirements for online data disclosure. This network for modernization, transparency and accountability, provided by the proposed solution of this work, presents itself as a very promising instrument in this regard.

\section{ACKNOWLEDGEMENT}

This work is financed by FEDER - European Regional Development Fund through COMPETE 2020 - Operational Programme for Competitiveness and Internationalisation $(\mathrm{POCI})$ and by national funds through FCT - Foundation for Science and Technology, with the reference POCI-01-0145-FEDER-016869.

\section{REFERENCES}

Ball, C. (2009). What Is Transparency?. Public Integrity, 11(4), 293-308. https://doi.org/10.2753/PIN1099-9922110400

Bender, A., Spring, N, Levin, D. and Bhattacharjee, B. (2007). Accountability as a Service. SRUTI, 7, 1-6. Available at: http://static.usenix.org/event/sruti07/tech/full_papers/bender/bender.pdf (Accessed: 19 May 2019).

Bertot, J. C., Jaeger, P. T. and Grimes, J. M. (2010). Using ICTs to create a culture of transparency: E-government and social media as openness and anti-corruption tools for societies. Government Information Quarterly, 27(3), $264-271$. https://doi.org/10.1016/j.giq.2010.03.001

Christensen, L. T. and Cornelissen, J. (2015). Organizational transparency as myth and metaphor. European Journal of Social Theory, 18(2), 132-149. https://doi.org/10.1177/1368431014555256

Connolly, C. and Kelly, M. (2011). Understanding accountability in social enterprise organisations: a framework. Social Enterprise Journal, 7(3), 224-237. https://doi.org/10.1108/17508611111182386 
Cotterrell, R. (1999). Transparency, mass media, ideology and community. Cultural Values, 3(4), 414-426. https://doi.org/10.1080/14797589909367176

Devlieghere, J., Bradt, L. and Roose, R. (2019). Electronic information systems as means for accountability: why there is no such thing as objectivity. European Journal of Social Work. Routledge. https://doi.org/10.1080/13691457.2019.1585335

Ferreira, A., Marques, R. P., Santos, C. and do Carmo Azevedo, G. M. (2019). Evaluation of the Online Accountability of the Portuguese Private Institutions of Social Solidarity. In Ferreira, A., et al. (eds) Modernization and Accountability in the Social Economy Sector. Hershey, PA: IGI-Global. https://doi.org/10.4018/978-1-5225-8482-7.ch011

Ferreira, A., Marques, R. P., Santos, C., Azevedo, G. and Mendes, H. (2016). Avaliação da Presença na Internet das Instituições Particulares de Solidariedade Social Portuguesas. Estudos do ISCA, (14). https://doi.org/10.1234/ei.v0i14.4730

Guo, Z. and Ma, D. (2018). A Model of Competition Between Perpetual Software and Software as a Service. MIS Quarterly, 42(1), 101-120. https://doi.org/10.25300/MISQ/2018/13640

Gustavsson, M. (2017). Digital Platforms as dislocators on digitalization and limits of discourse. University of Gothenburg.

Hevner, A. and Chatterjee, S. (2010). Design Science Research in Information Systems. In Design Research in Information Systems. Springer US, pp. 9-22. https://doi.org/10.1007/978-1-4419-5653-8_2

Hevner, A. R. (2007). Scandinavian Journal of Information Systems A Three Cycle View of Design Science Research A Three Cycle View of Design Science Research. Scandinavian Journal of Information Systems @ Scandinavian Journal of Information Systems, 19(192), 87-92. Available at: http://aisel.aisnet.org/sjis (Accessed: 25 May 2018).

Karatas, G., Can, F., Dogan, G., Konca, C. and Akbulut, A. (2017). Multi-tenant architectures in the cloud: A systematic mapping study. In 2017 International Artificial Intelligence and Data Processing Symposium (IDAP). IEEE, pp. 1-4. https://doi.org/10.1109/IDAP.2017.8090268

Kenney, M. and Zysman, J. (2016). The Rise of the Platform Economy. Issues in Science \& Technology, 32(3), 61-69. https://doi.org/10.17226/21913

Lewandowski, C. M. (2013). Choosing a future in platform economy. Journal of Chemical Information and Modeling, 53(18), 16891699. https://doi.org/10.1017/CB09781107415324.004

Li, Q. and Liu, K. (2016). Interactive data visualisation: Facilitate the accountability disclosure through the lens of organisational semiotics. In IFIP Advances in Information and Communication Technology. Springer New York LLC, pp. $133-142$. https://doi.org/10.1007/978-3-319-42102-5_15

Marques, R. P., Santos, C. and Duarte, R. (2019). Uma Plataforma Web Baseada numa Arquitetura SaaS Multi-Tenant para Promover a Accountability do Setor da Economia Social. In Atas da Conferencia da Associacao Portuguesa de Sistemas de Informacao. Lisboa: Associação Portuguesa de Sistemas de Informação.

Marques, R. P., Santos, C. and Duarte, R. (2020). Promotion of Accountability and Performance of the Social Economy Entities with SaaS Multi-Tenant Information Systems. In 2020 15th Iberian Conference on Information Systems and Technologies (CISTI). IEEE, pp. 1-6. https://doi.org/10.23919/CISTI49556.2020.9140813

Marrone, M. and Hazelton, J. (2019). The disruptive and transformative potential of new technologies for accounting, accountants and accountability: A review of current literature and call for further research. Meditari Accountancy Research, 27(5), 677-694. https://doi.org/10.1108/MEDAR-06-2019-0508

Marshall, M., Vines, J., Wright, P., Kirk, D. S., Lowe, T. and Wilson, R. (2018). Accountability work: Examining the values, technologies and work practices that facilitate transparency in Charities. In Conference on Human Factors in Computing Systems Proceedings. New York, New York, USA: Association for Computing Machinery, pp. 1-12. https://doi.org/10.1145/3173574.3173849

Meijer, A. (2015). Government Transparency in Historical Perspective: From the Ancient Regime to Open Data in The Netherlands. International Journal of Public Administration, 38(3), 189-199. https://doi.org/10.1080/01900692.2014.934837

Myers, M. D. (1997). Critical Ethnography in Information Systems. In Information Systems and Qualitative Research. Springer US, pp. 276-300. https://doi.org/10.1007/978-0-387-35309-8_15

Peffers, K., Tuunanen, T., Rothenberger, M. A. and Chatterjee, S. (2007). A Design Science Research Methodology for Information Systems Research. Journal of Management Information Systems, 24(3), 45-77. https://doi.org/10.2753/MIS0742-1222240302

Rawlins, B. (2009). Give the emperor a mirror: toward developing a stakeholder measurement of organizational transparency. Journal of public relations research: a quarterly publication of the Public Relations Division of the Association for Education in Journalism and Mass Communication, 21(1), 71-99. https://doi.org/10.1080/10627260802153421

Rong, K., Lin, Y., Shi, Y. and Yu, J. (2013). Linking business ecosystem lifecycle with platform strategy: a triple view of technology, application and organization: International Journal of Technology Management, 62(1), 75. https://doi.org/10.1504/IJTM.2013.053042

Santos, C., da Conceição Santos Ferreira, A., Figueiredo Marques, R. P. and do Carmo Azevedo, G. M. (2018). EAGLE_Index: Enhancement of an accountability guide for learning E-Government. Handbook of Research on Modernization and Accountability in Public Sector Management. https://doi.org/10.4018/978-1-5225-3731-1.ch006

Santos, C., da Conceição Santos Ferreira, A., Figueiredo Marques, R. P., do Carmo Azevedo, G. M. and Inácio, H. (2019). Modernization and Accountability in the Social Economy: A Systematic Review. In Ferreira, A., et al. (eds.) Modernization and Accountability in the Social Economy Sector. Hershey, PA: IGI-Global. https://doi.org/10.4018/978-1-5225-8482-7.ch001 
Tenbensel, T., Dwyer, J. and Lavoie, J. (2014). How not to kill the golden goose. Public Management Review, 16(7), 925-944. https://doi.org/10.1080/14719037.2013.770054

Tizzei, L. P., Nery, M., Marcelo Nery, Segura, V. C. V. B., Cerqueira, R. F. G. (2017). Using Microservices and Software Product Line Engineering to Support Reuse of Evolving Multi-tenant SaaS. In Proceedings of the 21st International Systems and Software Product Line Conference - Volume A on - SPLC '17. New York, New York, USA: ACM Press, pp. $205-214$. https://doi.org/10.1145/3106195.3106224

Truyen, E., Van Landuyt, D., Reniers, V., Rafique, A., Lagaisse, B. and Joosen, W. (2016). Towards a container-based architecture for multi-tenant SaaS applications. In Proceedings of the 15th International Workshop on Adaptive and Reflective Middleware. ACM; New York, NY, USA, pp. 1-6. https://doi.org/10.1145/3008167.3008173

Turilli, M. and Floridi, L. (2009). The ethics of information transparency. Ethics and Information Technology, 11(2), $105-112$. https://doi.org/10.1007/s10676-009-9187-9

Upward, A. and Jones, P. (2016). An Ontology for Strongly Sustainable Business Models. Organization \& Environment, 29(1), $97-123$. https://doi.org/10.1177/1086026615592933

US Air Force (2004). SMC Systems Engineering: Concepts, Processes, and Techniques (2nd ed.). Washington, D.C.: US Air Force.

Vaccaro, A. (2012). To Pay or Not to Pay? Dynamic Transparency and the Fight Against the Mafia's Extortionists. Journal of Business Ethics, 23-35. https://doi.org/10.2307/41413242

Windrum, P., Schartinger, D., Rubalcaba, L., Gallouj, F. and Toivonen, M. (2016). The co-creation of multi-agent social innovations: A bridge between service and social innovation research. European Journal of Innovation Management, 19(2), 150-166. https://doi.org/10.1108/EJIM-05-2015-0033

Yao, J., Chen, S., Wang, C., Levy, D. and Zic, J. (2010). Accountability as a Service for the Cloud. In 2010 IEEE International Conference on Services Computing. IEEE, pp. 81-88. https://doi.org/10.1109/SCC.2010.83

Zysman, J. and Kenney, M. (2017). The Next Phase in the Digital Revolution: Platforms, Automation, Growth, and Employment. CACM. 